\title{
BROWN FIELD REHABILITATION SUCCESS THROUGH AN EFFECTIVE PROJECT MANAGEMENT SYSTEM
}

\section{INTRODUCTION}

Laslau Mare is a mature gas field in Transylvania Basin. The field exploitation began in 1975 and has been operated since then by Romgaz.

In 2004 Romgaz entered into an Association agreement with Schlumberger to rehabilitate Laslau Mare field. Association's main goals for project rehabilitation has been maximization of field potential by increasing gas production and reservoir ultimate recovery factor. The incremental production, defined as the additional gas volume obtained above a production baseline negotiated at project inception is the key objective of Association.

According to Project Management Body of Knowledge (PMBOK®) framework from the Project Management Institute (PMI), the project management breaks in processes groups, knowledge area and professional and social responsibility all of them being integrated in a system approach.

This paper examines key aspects of the project management system processes, adapted to the oil and gas industry and implemented in our project to meet and exceed project goals.

Project Life Cycle is a series of sequential or iterative phases that a project passes through since initiation till closure. Figure 1 below shows the Laslau Mare project phases' defined in compliance to Schlumberger Production Management Governance Standard. Laslau Mare project is in the Operating phase in which most of the activities

* Schlumberger

** SNGN ROMGAZ SA, Romania 
such as candidates' selection, drilling, workovers, rigless operation or compressor installation are treated as projects that go through the Appraise - Select - Define - Execute sequential phases.

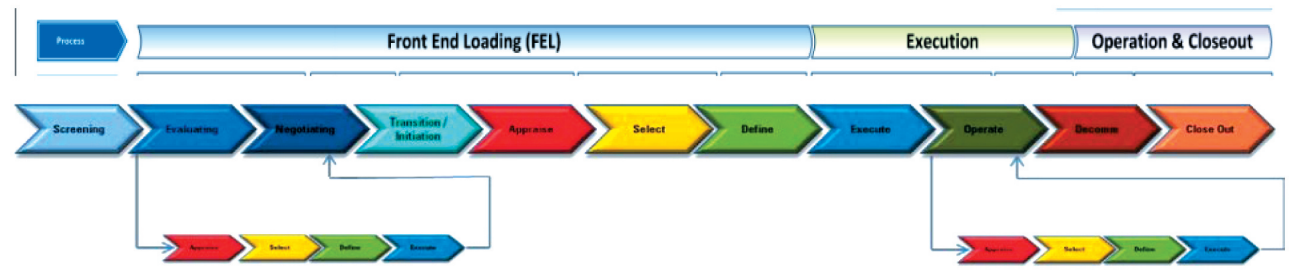

Fig. 1. Project Life Cycle model used in Laslau Mare Project

\section{STAKEHOLDER MANAGEMENT}

Stakeholders are individuals or organizations whose interests may be positively or negatively impacted by a project. Examples of our main group of stakeholders are: project team members, management, services and products suppliers, support functions departments (legal, procurement, commercialization, etc), host communities, and government. All these stakeholders have multiple interactions between them, through multiple communications channels that at a certain point in time may become chaotic and result in an undesired negative impact on project interest.

Stakeholders have to be continuously identified during the project lifecycle; a qualification of their level of project support and level of influence is mandatory to understand the stakeholders' needs, demands and expectations. Their support and influence are mapped as in the Figure 2 and the mapping should be updated before any significant milestone or in case of change within the stakeholders groups. Depending on stakeholders' level of influence and involvement in the project, actions are planned to be taken in order to shift their position into favorable quadrant. This process is critical for success of any project.

Failure in stakeholders identification or in understanding their expectation from project could lead to significant delays, increase in costs and even cancelation of projects. Communication with stakeholders has to be planned as any other project process; communication needs to be done with right impact, through effective channels in order to reach the desired outcome. Daily operational meeting, weekly project meeting, daily and monthly reports, quarterly rolling forecast presentation, peer technical review, periodical service quality meeting, biannual management steering committee meeting, are only few examples from Laslau Mare communication plan. 


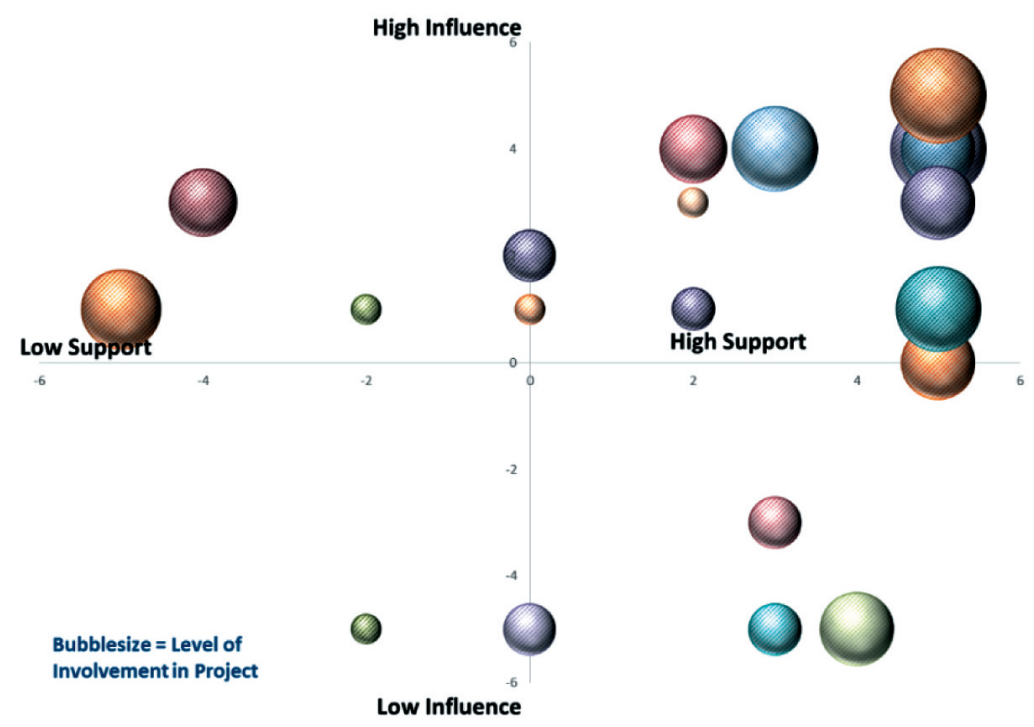

Fig. 2. Stakeholder management map

\section{PLANNING PROCESS}

The Annual Work Program (AWP) includes the definition of scope of work, the schedule and budget baseline to achieve the targeted incremental production, the necessary human resources, contracting strategy, risks and opportunities identification and analysis.

The AWP is supported by detailed activity plans for the forthcoming quarter and "frozen" on a monthly look ahead basis.

These plans are prepared by those who will be directly involved in their implementation together with interfacing parties and discipline groups in order to avoid potential scheduling clashes or unforeseen impacts.

Front End Engineering Design (FEED) is accomplished through a Front End Loading (FEL) approach that was applied in the industry for facilities type projects; the focus is on the early phases of engineering and design when the ability to influence changes in design is relatively high at relatively low cost comparing with changes done during execution phase. The Front End Loading approach leads to high value outcome/ realisation. This is assured by allocating experienced resources during project's early definition activities, when the execution trajectory and project outcome in terms of value delivered is locked at a high realisation value, as shown in Figure 3 below.

In Laslau Mare the FEL approach has been applied not only to facilities type projects but to any operations project; its benefits have similar reflection on cost, schedule and finally on production. 


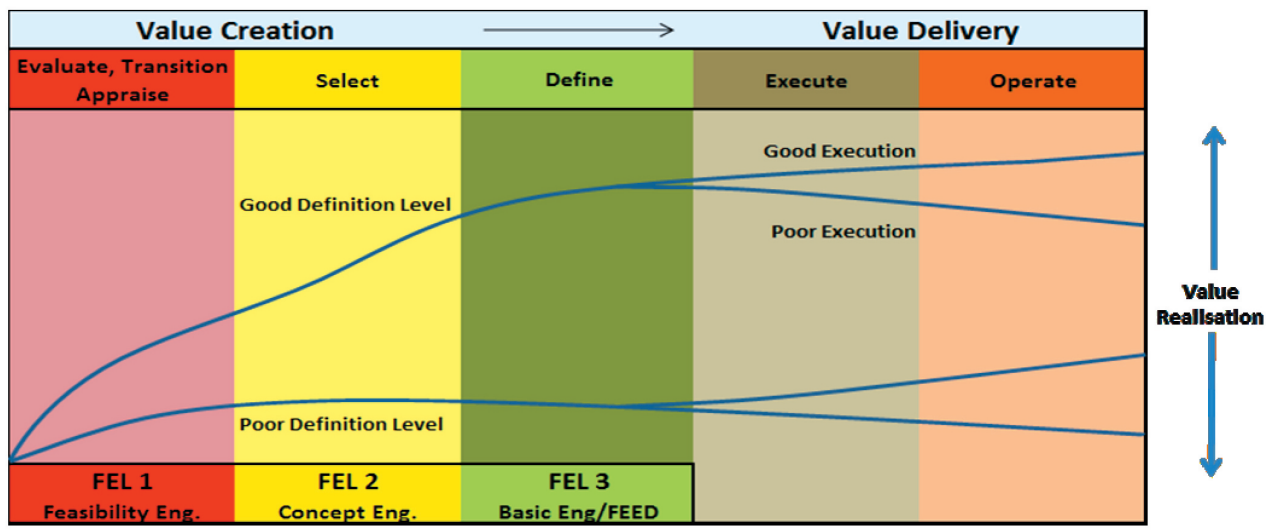

Fig. 3. Front End Loading illustartions

\section{FROM PROJECT MANAGEMENT TRIANGLE TO A PROJECT MANAGEMENT HEXAGON}

Scope-Budget-Schedule is known in the literature as the project management tradeoffs for the reason that one of three must be often sacrificed (Fig. 4)

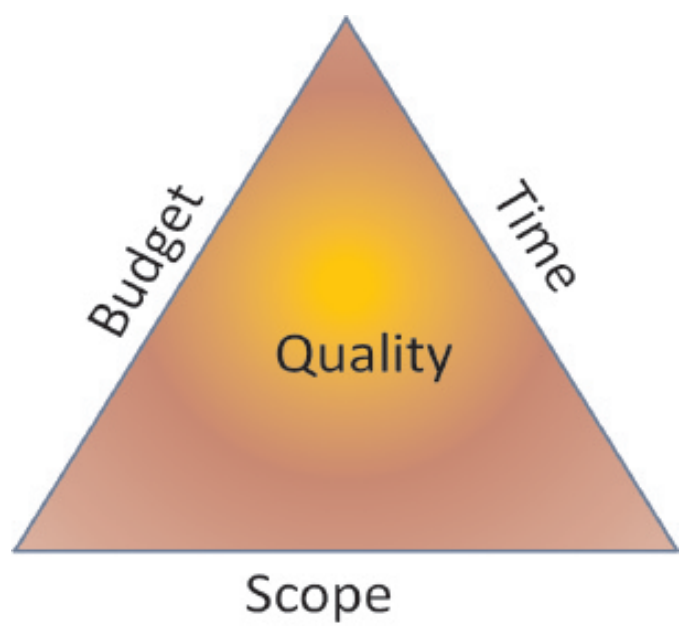

Fig. 4. Iron Triangle

In Laslau Mare project we consider balancing the six constraints Scope, Quality, Budget, Schedule, Resources and Risks in a model that I would call "Aquamarine Hexagon" as in the Figure 5. 


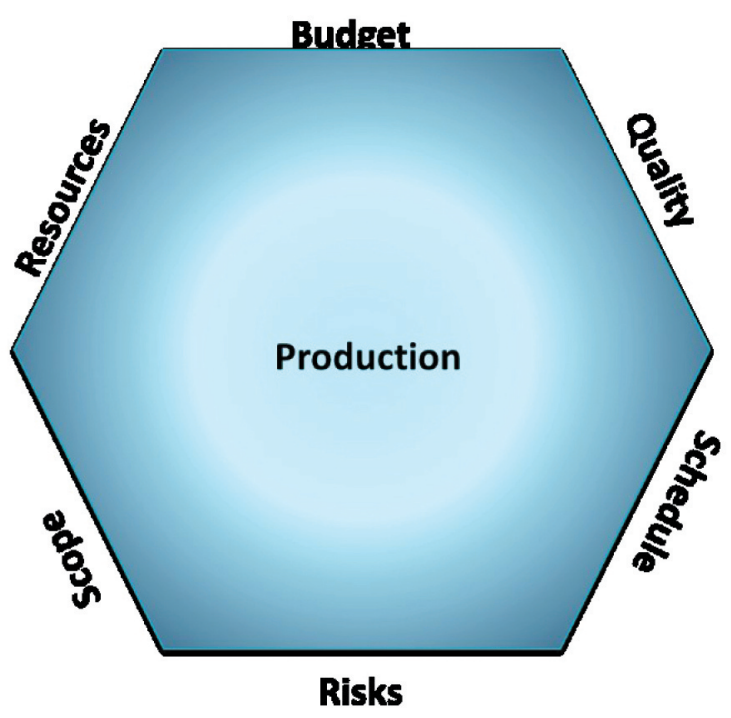

Fig. 5. "Aquamarine Hexagon"

It is critical to make an assessment of schedule and budget risks while defining the scope of work, budget and schedule baselines. The three baselines are considered planned outcomes. Due to unmanaged risks that directly impact one of the baseline, the final outcomes will be deviated.

A common example are operational risks assessment (such as stuck pipe during drilling) that may significantly increase the execution time, cost or even change the scope of work. But it is equally important to assess risks associated with procurement or logistic such as long lead products or tenders delays. Therefore a structured schedule and budget risks assessment is critical as it gives us a better estimate of budget or schedule boundary' range. Figure 6 shows an example of schedule probability S-Curve run as part of planning the installation of compressor in the field, an activity for which the schedule and budget were risk assessed.

Project team needs to be knowledgeable and skillful to balance the variable constraints and to assess the potential change. In these cases the project plan has to be reiterated and continuously improved. As an example for candidate selection team applied a lean methodology to define the workflow (Fig. 7) that involves Well Construction and Intervention, Production and Subsurface people.

Beside the six boundaries discussed above for Laslau Mare project, the incremental production is the "Produced Value" or "Primary Benefit". As a target element, incremental production will show how well the six interdependent constraints: Scope, Budget, Schedule, Quality, Risks and Resources are balanced within the boundary of the hexagon. 


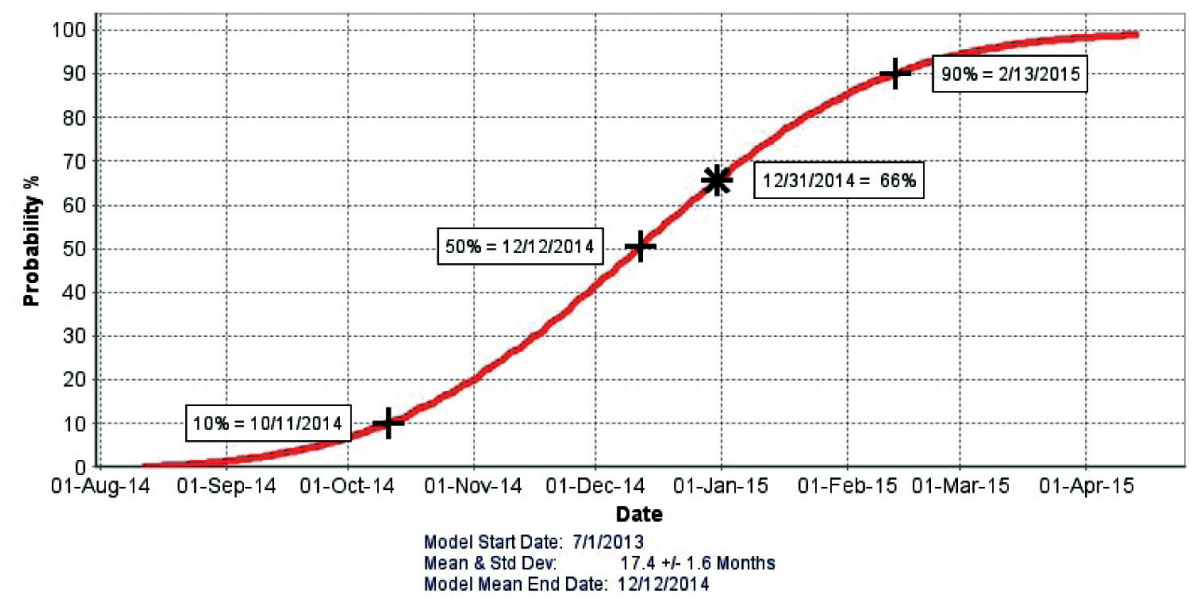

Fig. 6. Schedule Probability S-Curve

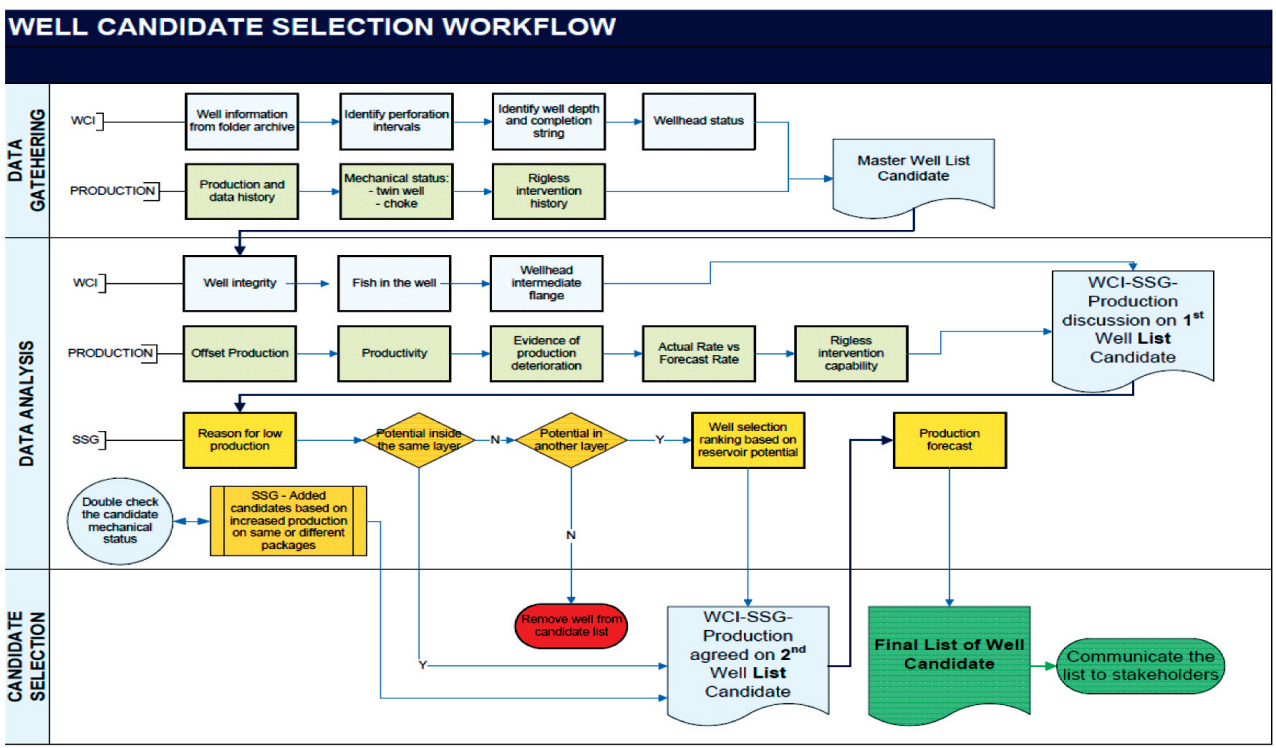

Fig. 7. Well candidate selection workflow

\section{RISK MANAGEMENT}

"Risk is an uncertain event or condition that, if it occurs, has a positive or negative effect on a project objective". The oil and gas projects are complex, facing multiple risks in all the phases of the project starting from the screening phase to the operation phase. 
These risks have a direct impact on the project schedule, cost, quality, HSE, including negative effects (threats) and positive effects (opportunities).

Risk Management is an iterative process implemented along the life of a project, as new risks may appear or evolve as the project progresses.

Risk management is documented in a Risk Register and follows the main steps below:

- Risks identification using a brainstorming technique performed by multi-domains representatives under the leadership of a facilitator.

- Risk analysis:

- Qualitative risk analysis that combines probability of occurrence (likelihood) with impact on project (severity).

- Quantitative risks assessment- an example is the Sensitivity Analysis technique that helps to rank the risks impact on project; Tornedo diagram is the typical representation of sensitivity analysis.

- Plan Risk Responses.

- Monitor and control risks that may result in identification of new risks, reassessment of current risks or the closing of risks which are outdated. Monitoring and Control of risks has to include documented lessons learned during risk management process.

Project manager, team leaders, project team members (ROMGAZ and SPM), subject matter experts outside of project, any other stakeholders such as suppliers participate in the Risk Management process.

Figure 8 shows a snapshot of the Laslau Mare Risk Register header.

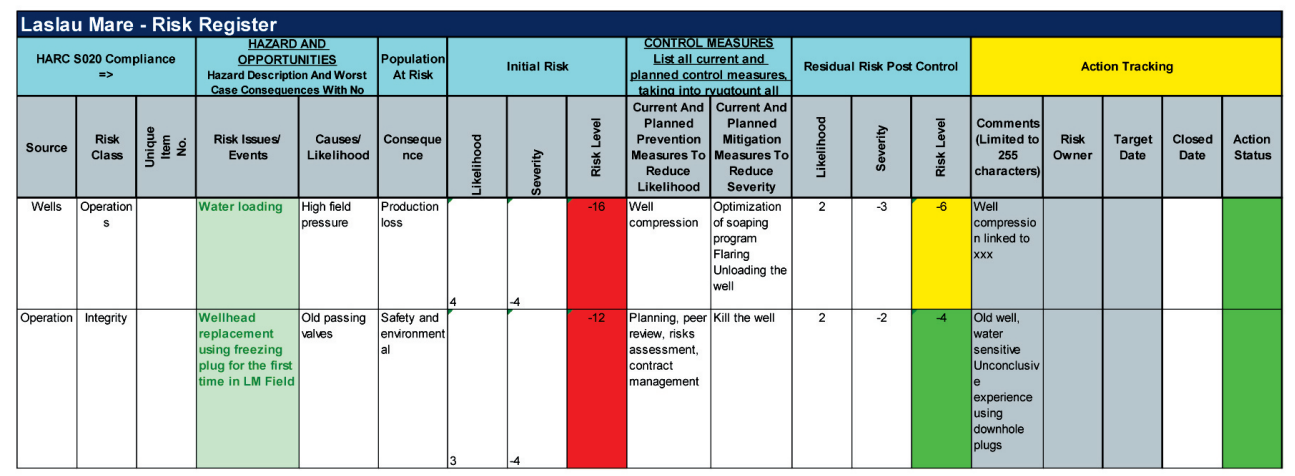

Fig. 8. Laslau Mare Risk Register snapshot

\section{PROJECT TEAM MANAGEMENT}

An experienced multidisciplinary team must be organized to work on the common goal of completing the project efficiently. Within Laslau Mare project, the team members 
have necessary expertise to integrate the following domains: Project Management, Geology, Reservoir Engineering, Production, Well Construction and Intervention, Field Operation, Facilities, Finance, Quality Assurance, Health Safety Social Environmental, Procurement, Contracting, Logistic and Legal.

Team is encouraged to actively contribute in all project domains. This approach leads to an effective communication within the team and an increased motivation level. An open and effective communication helps achieving a high team performance. The challenge of having team members from two organizations Romgaz and Schlumberger within the office and the field was overcome by a proper communication plan; collaborative attitude and effective working relationship becoming part of project team culture. Periodical formal and informal meetings together with a clear reporting system, enable information flow, faster decision and smother alignment during decision gates.

\section{MONITORING AND CONTROL PROCESS}

Monitoring and controlling are performed to monitor project processes. Few examples of monitoring and control in Laslau Mare project are below:

- Comparing actual performance against plan - actual versus plan analysis concerning production, time, cost and safety indicators is done monthly. Figure 9 below shows the dashboard included in the Association's monthly report.

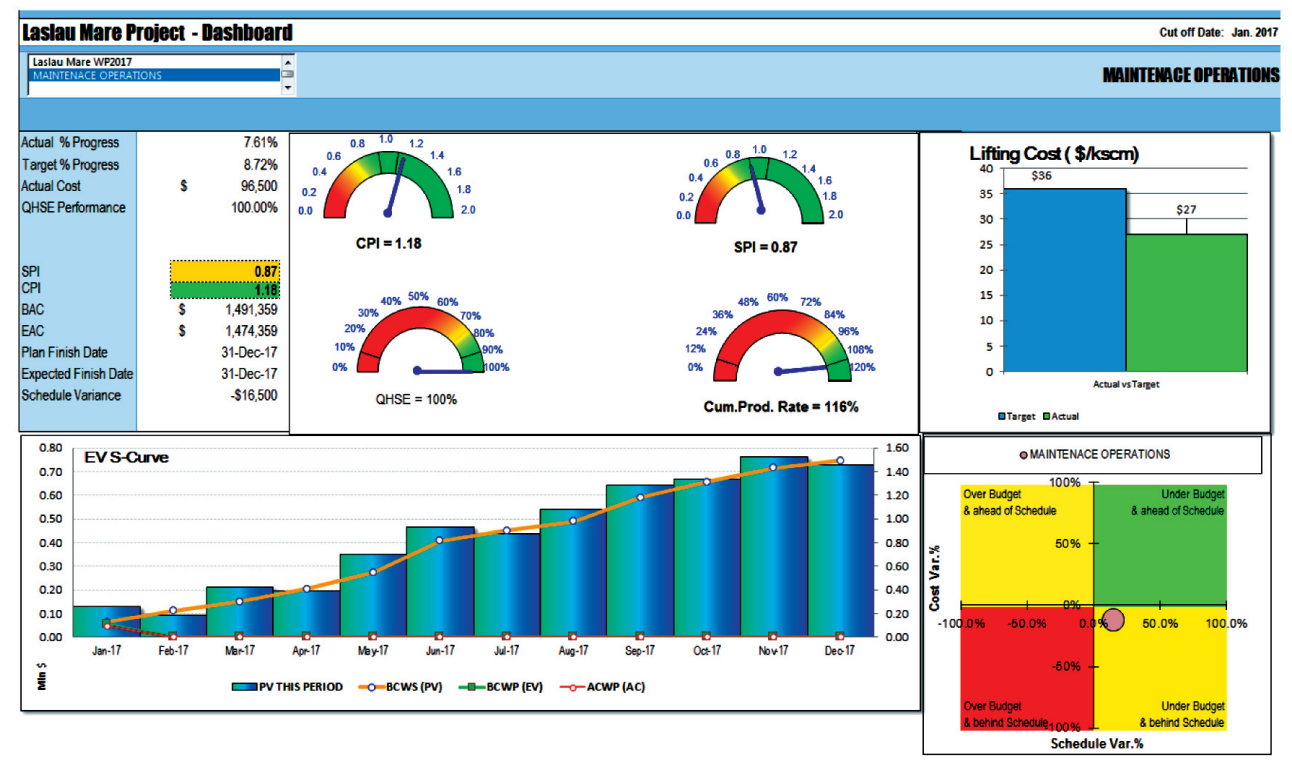

Fig. 9. Laslau Mare monthly dashboard 
- Risks management - periodical assessment of risks register.

- Providing forecasts to update current cost and schedule information - for next month forecast or quarterly rolling forecast.

- Monitoring implementation of approved changes. Change is defined as per SPM Management of Change standard as "any deviation or modification, addition, subtraction or deletion within an installation and/or organization to any approved philosophy, scope, plan, design, procedure, workflow that may impact the project delivery or ultimate Asset performance - that is detected after approval, but prior to execution". Typical example is a change of work scope or budget allocated considered a proactive decision taken in time before the execution. In a dynamic environment, the need to be agile in adopting the change is critical. Laslau Mare project has a management of change process implemented.

\section{PROJECT RESULTS}

The main factors measuring the success of Laslau Mare rehabilitation project are:

1. Health, Safety and Environment - zero incidents since project start.

2. Incremental production that reach four times the baseline as shown in the Figure 10.

3. Budget \& Schedule - Consistent closure of yearly program under the budget.

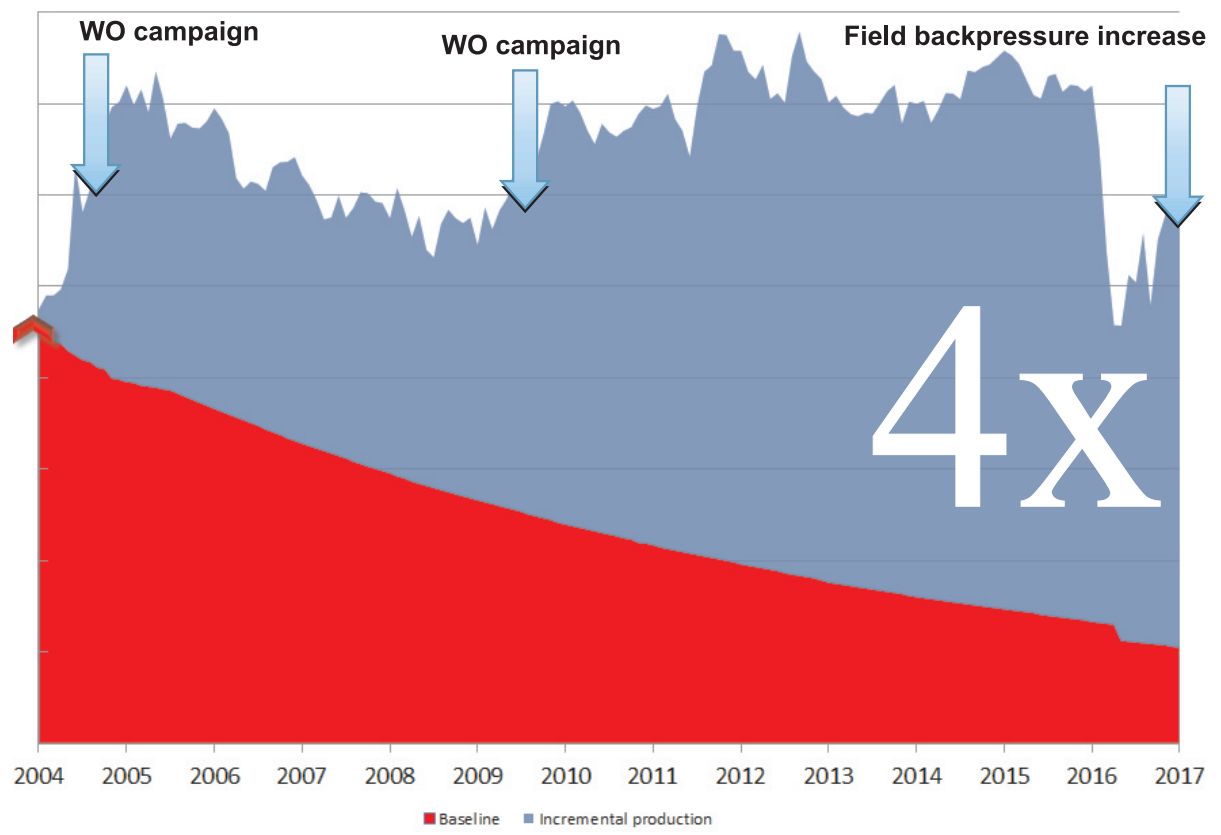

Fig. 10. Laslau Mare field production 


\section{CONCLUSION}

With the industry facing the potential of an extended oil price downturn, the focus has rightly shifted to minimizing the investment and maximizing their Return on Investment through production optimization. Effective project management methodology is paramount to achieving this. The success story of Laslau Mare gas field rehabilitation project has highlighted the key aspects of processes that had significant contribution to the success of the project as presented here: stakeholder management, effective project team management, proactive and detailed planning, and clear risks management process, continuous monitoring and control.

\section{REFERENCES}

[1] Project Management Institute: A Guide to the Project Management Body of Knowledge. $\mathrm{PMBOK}{ }^{\circledR}$ Guide.

[2] SPM Governance Framework: SPM-QAS-GD-001.

[3] SPM Standard Operating Practices: Management of Changes: IMP-SPM-QAS-SOP-010.

[4] Badiru A.B., Osisanya S.O.: Project Management for the Oil and Gas Industry: A World System Approach. CRC Press, 2013. DOI: 10.1201/b13755.

[5] SPM Facilities Engineering and Constructions Front end Engineering: SPM-FEC-SOP-001.

[6] https:/www.inloox.com/company/blog/articles/the-magic-triangle-and-devil-s-quadrangle-understanding-project-management-models/. 